\title{
Converting laparoscopic colectomies to open is associated with similar outcomes as a planned open approach among Crohn's disease patients
}

\author{
Rebecca Sahyoun ${ }^{1}$ - Brian D. Lo ${ }^{1}$. George Q. Zhang ${ }^{1} \cdot$ Miloslawa Stem $^{1}$. Chady Atallah ${ }^{1}$ - Peter A. Najjar ${ }^{1}$. \\ Jonathan E. Efron ${ }^{1} \cdot$ Bashar Safar ${ }^{1}[1$
}

Accepted: 19 August 2021 / Published online: 5 October 2021

(c) The Author(s), under exclusive licence to Springer-Verlag GmbH Germany, part of Springer Nature 2021

\begin{abstract}
Purpose There has been a noted reluctance to offer laparoscopic surgery to Crohn's Disease patients due to the potential risks, and high rate, of converting the procedure to open. The purpose of this study was to compare clinical outcomes between Crohn's Disease patients undergoing a planned open colectomy, to those undergoing a laparoscopic colectomy that was converted to open.

Methods Crohn's Disease patients undergoing an elective colectomy were identified using the ACS-NSQIP database (2012-2019). Patients were stratified based on operative approach: open, laparoscopic, and laparoscopic converted to open. Multivariable logistic regression was used to assess the impact of conversion to open on overall and serious postoperative morbidity.

Results Among 8039 elective colectomies, $40.5 \%$ were performed open, $46.9 \%$ were completed laparoscopically, and $12.6 \%$ were converted to open. The conversion rate among all laparoscopic cases was $21.3 \%$. On unadjusted analysis, conversion to open demonstrated similar rates of overall morbidity $(P=0.355)$ and serious morbidity $(P=0.724)$ compared to a planned open approach. On multivariable analysis, conversion to open was not associated with increased odds of overall morbidity (OR $1.12,95 \%$ CI $0.94-1.30, P=0.238$ ) or serious morbidity (OR 1.20, 95\% CI 0.98-1.46, $P=0.074$ ), when compared to an open approach.

Conclusion Among Crohn's Disease patients, cases converted from laparoscopic to open exhibited similar outcomes as a planned open approach. Despite the limitations associated with this retrospective study, our findings suggest that laparoscopic surgery may be safely pursued among Crohn's Disease patients, as the risks of conversion are potentially balanced by the benefits of laparoscopic surgery.
\end{abstract}

Keywords Laparoscopic surgery $\cdot$ Crohn's disease $\cdot$ Colectomy $\cdot$ Conversion to open $\cdot$ Open surgery $\cdot$ Outcomes

This abstract was accepted for a quick-shot oral presentation during the 2020 Digestive Disease Week Annual Meeting from May 2-5, 2020 in Chicago, IL, United States. However, the conference was cancelled due to COVID-19.

Bashar Safar

bsafar1@jhmi.edu

1 Department of Surgery, Colorectal Research Unit, Ravitch Division of Colorectal Surgery, Johns Hopkins University School of Medicine, 600 N. Wolfe Street, Blalock 618, MD 21287 Baltimore, USA

\section{Introduction}

Crohn's disease (CD) is a chronic, inflammatory disease of the gastrointestinal tract that primarily affects the small intestine and colon. In North America, there are approximately 400,000-600,000 patients living with CD, with $9000-44,000$ individuals diagnosed annually [1]. CD is associated with significantly increased morbidity and decreased quality of life, which renders the burden of this illness on individuals quite high, with an estimated lifetime cost of $\$ 622,000$ USD [2]. Furthermore, given its naturally relapsing and remitting inflammatory course, this condition can ultimately result in either a stricturing or perforating 
phenotype, both of which require surgical intervention. Ultimately, $3-5 \%$ of CD patients will undergo surgery every year [3].

Previously, an open approach was the predominant method for performing bowel resections in CD. However, with the emergence of minimally invasive surgery and the advantages it provides, laparoscopic colectomies have become the first-line surgical approach. The safety of a laparoscopic approach has been proven in both primary and recurrent disease [4]. A meta-analysis assessing the feasibility of the laparoscopic approach for CD revealed that patients who underwent laparoscopic procedures had faster return of bowel function, earlier tolerance of oral intake, shorter duration of hospitalization, and lower morbidity compared to those who underwent an open approach [4-6].

Though these advantages are appealing, the risk of conversion to open may limit the benefits of laparoscopy. Length of stay and wound complications seem to be the most negatively affected outcomes due to conversion [7, 8]. This is of particular concern in $\mathrm{CD}$, as this disease process is independently associated with an increased risk of conversion from laparoscopic to open in colorectal surgery [7, 9-14]. To date, limited data exist comparing laparoscopic converted to open versus planned open colectomy among CD patients, making it unclear whether the worse outcomes associated with conversion offset the advantages of laparoscopy.

The purpose of this study was to assess the association between conversion to open and postoperative morbidity among CD patients undergoing an elective colectomy. We hypothesize that colectomies converted from laparoscopic to open will exhibit similar outcomes to a planned open approach.

\section{Methods}

\section{Data source}

This was a retrospective analysis using the 2012-2019 American College of Surgeons - National Surgical Quality Improvement Program (ACS-NSQIP) participant use data file and colectomy procedure-targeted file. This national risk-adjusted, audited, and validated database was developed by surgeons and includes data from patients' medical charts, not insurance claims. Certified surgical clinical reviewers prospectively collect this data on more than 150 perioperative variables from over 700 NSQIP-participating sites $[15,16]$. This study was reviewed and approved by the Institutional Review Board of the Johns Hopkins University School of Medicine.

\section{Study population}

Patients undergoing a colectomy (Current Procedural Terminology [CPT] codes 44140, 44160, 44204, 44205) for a primary indication of $\mathrm{CD}$ were included. $\mathrm{CD}$ was defined using NSQIP's primary indication for surgery variable. Only laparoscopic (with or without conversion to open resection) and open operative approaches were considered and defined using the NSQIP operative approach variable. Patients were excluded if they met any of the following exclusion criteria: a) underwent surgical approaches other than laparoscopic or open, b) had diverticulitis, ulcerative colitis, and/or colon cancer diagnoses, c) underwent a stoma-creating procedure, or d) underwent an emergent procedure. Patients were stratified into three groups based on operative approach: open (planned and completed) colectomy, laparoscopic (completed) colectomy, and laparoscopic (converted to open) colectomy.

\section{Baseline characteristics of patients}

Demographic and clinical characteristics were compared between the three groups of interest. Demographic characteristics included: age ( $<30,30-39,40-49,50-59$, and $\geq 60$ years), sex, and race (White, Black, other/unknown [American Indian/ Alaskan Native, Native Hawaiian/Pacific Islander, Asian]). Clinical characteristics included: the American Society of Anesthesiologists (ASA) Physical Status Classification ("I-II" no or mild disturbance; "III" severe disturbance; "IV-V" life-threatening and moribund), obesity (body mass index $[\mathrm{BMI}] \geq 30 \mathrm{~kg} / \mathrm{m}^{2}$ ) and preoperative comorbidities: diabetes mellitus (oral agents or insulin), current smoker, chronic steroid use, dyspnea, chronic obstructive pulmonary disease (COPD), hypertension requiring medication, bleeding disorder, weight loss $(>10 \%$ decrease in body weight in the past six months), and preoperative transfusion. Preoperative variables included lab values of hematocrit, white blood cell count, blood urea nitrogen, and creatinine (all categorized as abnormal, normal, and unknown [17-19]), as well as preoperative sepsis, mechanical bowel preparation, and preoperative oral antibiotics. Other variables included: concurrent organ removal procedure (gynecologic or small bowel [CPT codes 58150, 58180, 58200, 58210, 58550, 58570, 58571, 58552, 58940, 58700, 44120, 44121, 44202, 44203]), concurrent fistula (CPT codes 44640, 44650, 44660, 44661, 50930), and type of resection (segmental [CPT 44140 and 44204] or ileocolic [CPT 44160 and 44205] resection).

\section{Outcomes}

The primary outcome was overall morbidity, defined as the occurrence of one or more of the following adverse events within 30 days of surgery: wound infection, pneumonia, 
Table 1 Demographic, clinical, and operative characteristics for Crohn's Disease patients undergoing an elective colectomy, stratified by operative approach

\begin{tabular}{|c|c|c|c|c|c|}
\hline \multirow[t]{2}{*}{ Characteristic, n (\%) } & $\begin{array}{l}\text { Laparoscopic } \\
\text { converted to open }\end{array}$ & Open & $p^{a}$ & Laparoscopic & \multirow[t]{2}{*}{$p^{b}$} \\
\hline & 1017 (12.6) & $3253(40.5)$ & & $3769(46.9)$ & \\
\hline Age group, years & & & 0.001 & & $<0.001$ \\
\hline$<30$ & 223 (21.9) & $613(18.8)$ & & $1247(33.1)$ & \\
\hline $30-39$ & $254(25.0)$ & $697(21.4)$ & & $951(25.2)$ & \\
\hline $40-49$ & $189(18.6)$ & $624(19.2)$ & & $618(16.4)$ & \\
\hline $50-59$ & $157(15.4)$ & $653(20.1)$ & & $473(12.6)$ & \\
\hline$\geq 60$ & $194(19.1)$ & $666(20.5)$ & & $480(12.7)$ & \\
\hline Sex & & & 0.005 & & $<0.001$ \\
\hline Male & $565(55.6)$ & $1642(50.5)$ & & $1589(42.2)$ & \\
\hline Female & $452(44.4)$ & $1611(49.5)$ & & $2180(57.8)$ & \\
\hline Race & & & 0.205 & & 0.316 \\
\hline White & $801(78.8)$ & $2578(79.3)$ & & $3008(79.8)$ & \\
\hline Black & $97(9.5)$ & 349 (10.7) & & $304(8.1)$ & \\
\hline Other ${ }^{\mathrm{c}} /$ Unknown & $119(11.7)$ & $326(10.0)$ & & $457(12.1)$ & \\
\hline ASA classification & & & $<0.001$ & & $<0.001$ \\
\hline I-II & $626(61.6)$ & $1620(49.9)$ & & $2573(68.3)$ & \\
\hline III & $386(38.0)$ & $1591(49.0)$ & & $1172(31.1)$ & \\
\hline IV-V & $4(0.4)$ & $39(1.2)$ & & $21(0.6)$ & \\
\hline $\mathrm{BMI} \geq 30 \mathrm{~kg} / \mathrm{m} 2$ & $232(23.0)$ & $614(19.1)$ & 0.007 & $693(18.5)$ & 0.002 \\
\hline Diabetes & $41(4.0)$ & $106(3.3)$ & 0.238 & $100(2.7)$ & 0.021 \\
\hline Current smoker & $235(23.1)$ & $901(27.7)$ & 0.004 & $758(20.1)$ & 0.037 \\
\hline Steroid use & $664(65.3)$ & $2026(62.6)$ & 0.119 & $2437(65.1)$ & 0.898 \\
\hline Dyspnea & $19(1.9)$ & $85(2.6)$ & 0.179 & $63(1.7)$ & 0.668 \\
\hline COPD & $11(1.1)$ & $62(1.9)$ & 0.077 & $32(0.9)$ & 0.485 \\
\hline Hypertension & $200(19.7)$ & $624(19.2)$ & 0.733 & $482(12.8)$ & $<0.001$ \\
\hline Bleeding disorder & $28(2.8)$ & $87(2.7)$ & 0.892 & $55(1.5)$ & 0.005 \\
\hline$>10 \%$ weight loss & $85(8.4)$ & $345(10.6)$ & 0.038 & $254(6.7)$ & 0.074 \\
\hline Pre-op transfusion & $10(1.0)$ & $39(1.2)$ & 0.573 & $16(0.4)$ & 0.031 \\
\hline Pre-op hematocrit & & & $<0.001$ & & 0.001 \\
\hline Abnormal & $357(35.1)$ & $1451(44.6)$ & & $1128(29.9)$ & \\
\hline Normal & $610(60.0)$ & $1669(51.3)$ & & $2378(63.1)$ & \\
\hline Unknown & $50(4.9)$ & $133(4.1)$ & & $263(7.0)$ & \\
\hline Pre-op white blood cell count & & & 0.181 & & 0.006 \\
\hline Abnormal & $292(28.7)$ & $1025(31.5)$ & & $966(25.6)$ & \\
\hline Normal & $672(66.1)$ & $2083(64.0)$ & & $2510(66.6)$ & \\
\hline Unknown & $53(5.2)$ & $145(4.5)$ & & $293(7.8)$ & \\
\hline Pre-op BUN & & & 0.024 & & 0.004 \\
\hline Abnormal & $185(18.2)$ & $711(21.9)$ & & $572(15.2)$ & \\
\hline Normal & $735(72.3)$ & $2279(70.1)$ & & $2719(72.1)$ & \\
\hline Unknown & $97(9.5)$ & $263(8.1)$ & & 478 (12.7) & \\
\hline Pre-op creatinine & & & 0.005 & & $<0.001$ \\
\hline Abnormal & $587(57.7)$ & $2061(63.4)$ & & $2352(62.4)$ & \\
\hline Normal & $355(34.9)$ & $997(30.7)$ & & $1038(27.5)$ & \\
\hline Unknown & $75(7.4)$ & $195(6.0)$ & & $379(10.1)$ & \\
\hline Mechanical bowel prep & & & $<0.001$ & & 0.757 \\
\hline No & $350(34.4)$ & $1344(41.3)$ & & $1327(35.2)$ & \\
\hline Yes & $538(52.9)$ & $1507(46.3)$ & & 1945 (51.6) & \\
\hline Unknown & $129(12.7)$ & $402(12.4)$ & & $497(13.2)$ & \\
\hline
\end{tabular}


Table 1 (continued)

\begin{tabular}{|c|c|c|c|c|c|}
\hline \multirow[t]{2}{*}{ Characteristic, n (\%) } & $\begin{array}{l}\text { Laparoscopic } \\
\text { converted to open }\end{array}$ & Open & $p^{a}$ & Laparoscopic & \multirow[t]{2}{*}{$p^{b}$} \\
\hline & $1017(12.6)$ & $3253(40.5)$ & & $3769(46.9)$ & \\
\hline Pre-op oral antibiotic & & & $<0.001$ & & 0.480 \\
\hline No & $384(37.8)$ & $1482(45.6)$ & & $1443(38.3)$ & \\
\hline Yes & $529(52.0)$ & $1436(44.1)$ & & $1897(50.3)$ & \\
\hline Unknown & $104(10.2)$ & $335(10.3)$ & & $429(11.4)$ & \\
\hline Concurrent organ removal $^{\mathrm{d}}$ & $95(9.3)$ & $339(10.4)$ & 0.320 & $171(4.5)$ & $<0.001$ \\
\hline Concurrent fistula & $69(6.8)$ & $238(7.3)$ & 0.567 & $110(2.9)$ & $<0.001$ \\
\hline Preoperative sepsis & $61(6.0)$ & $259(8.0)$ & 0.038 & $126(3.6)$ & $<0.001$ \\
\hline Resection type & & & 0.368 & & 0.276 \\
\hline Segmental resection & $206(20.3)$ & $702(21.6)$ & & $823(21.8)$ & \\
\hline Ileocolic resection & $811(79.7)$ & $2551(78.4)$ & & $2946(78.2)$ & \\
\hline
\end{tabular}

$S D$ standard deviation, $A S A$ American Society of Anesthesiologists, $B M I$ body mass index, $C O P D$ chronic obstructive pulmonary disease, $B U N$ blood urea nitrogen

${ }^{a}$ Laparoscopic converted to open vs. open colectomy

${ }^{\mathrm{b}}$ Laparoscopic converted to open vs. laparoscopic colectomy

${ }^{c}$ Asian, Native Hawaiian/Pacific Islander, or American Indian/Alaska Native

${ }^{\mathrm{d}}$ Gynecologic or small bowel organ removal

urinary tract infection (UTI), venous thromboembolic event (VTE), cardiac complication, shock/sepsis, unplanned intubation, bleeding requiring transfusion, renal complication, ventilator usage $>48 \mathrm{~h}$, organ/space surgical site infection (SSI), and/or anastomotic leak (AL). The secondary outcome of interest was serious morbidity, defined using Clavien-Dindo classification [20], and applied to the NSQIP-defined complications in the following manner: III - cardiac and renal complications, organ space SSI or reoperation and IV-shock/sepsis, unplanned intubation, or being on a ventilator $>48 \mathrm{~h}$. Other outcomes of interest included 30-day readmission, reoperation, mortality, ileus, length of stay (LOS) measured as days from operation to discharge, and operative time. Readmission is defined by NSQIP as admission to the same or another hospital for any reason.

\section{Statistical analysis}

Patients were classified into three groups based on operative approach. Student's $t$-test was used for continuous variables and Pearson's Chi-square test or Fisher's exact (when appropriate) for categorical variables. Multivariable logistic regression analysis was used to assess the association between operative approach and postoperative morbidity. All covariates with $P<0.25$ from the univariate analysis were included in the multivariable analysis, as recommended by Hosmer and Lemeshow [21]. Statistical significance was defined as $P<0.05$. All statistical analyses were performed using Stata, version 14.0 (StataCorp, College Station, Texas, USA).

\section{Results}

\section{Study population}

A total of 8039 patients were identified for inclusion, of which $40.5 \%$ underwent an open colectomy, $46.9 \%$ underwent a completed laparoscopic colectomy, and $12.6 \%$ underwent a laparoscopic colectomy that was converted to open. The conversion rate among all laparoscopic cases was $21.3 \%$ (1017 of 4786).

Demographic, clinical, and operative characteristics were compared between the three operative groups (Table 1). Patients who required an unplanned conversion to open tended to be younger, healthier, and exhibit less preoperative sepsis and weight loss, but were more likely to be obese when compared with the planned open approach group $(P<0.05$ for all). However, when compared to the laparoscopic group, patients undergoing an unplanned conversion tended to be older, sicker, and more obese, with abnormal preoperative lab results and preoperative sepsis $(P<0.05$ for all). These patients also more frequently underwent concurrent organ removal (gynecological or small bowel resections) and concurrent fistula procedures $(P<0.05$ for all) (Table 1$)$.

\section{Unadjusted outcomes}

No significant differences were observed between patients undergoing a planned open approach and a converted procedure, with respect to overall morbidity, serious morbidity, readmission, reoperation, ileus, and mortality (Table 2). However, the conversion group did have longer operative 
Table 230 day post-operative outcomes for Crohn's Disease patients undergoing an elective colectomy, stratified by operative approach

\begin{tabular}{|c|c|c|c|c|c|}
\hline Outcome (\%) & $\begin{array}{l}\text { Laparoscopic } \\
\text { converted to open } \\
1017(12.6)\end{array}$ & Open 3253 (40.5) & $p^{a}$ & $\begin{array}{l}\text { Laparoscopic } \\
3769(46.9)\end{array}$ & $p^{b}$ \\
\hline Overall morbidity $^{c}$ & $274(26.9)$ & $925(28.4)$ & 0.355 & 515 & $<0.001$ \\
\hline Serious morbidity ${ }^{\mathrm{d}}$ & $167(16.4)$ & $519(16.0)$ & 0.724 & $283(7.5)$ & $<0.001$ \\
\hline Readmission & $152(17.6)$ & $489(17.4)$ & 0.897 & 324 & $<0.001$ \\
\hline Reoperation & $50(4.9)$ & $177(5.4)$ & 0.515 & $115(3.0)$ & 0.004 \\
\hline Mortality & $1(0.1)$ & $10(0.3)$ & 0.251 & $2(0.1)$ & 0.609 \\
\hline Ileus & $204(20.1)$ & $649(20.0)$ & 0.935 & $362(9.6)$ & $<0.001$ \\
\hline LOS (days), mean \pm SD & $6.1 \pm 7.6$ & $6.6 \pm 9.3$ & 0.162 & $4.9 \pm 7.6$ & $<0.001$ \\
\hline Operative time, mean \pm SD & $188 \pm 73$ & $166 \pm 83$ & $<0.001$ & $152 \pm 66$ & $<0.001$ \\
\hline \multicolumn{6}{|l|}{ Individual complications } \\
\hline Wound infection ${ }^{\mathrm{e}}$ & $67(6.6)$ & $255(7.8)$ & 0.187 & $130(3.5)$ & $<0.001$ \\
\hline Pneumonia & $9(0.9)$ & $45(1.4)$ & 0.214 & $30(0.8)$ & 0.779 \\
\hline Anastomotic leak & $42(4.1)$ & $159(4.9)$ & 0.319 & $117(3.1)$ & 0.105 \\
\hline Urinary tract infection & $11(1.2)$ & $52(1.6)$ & 0.233 & $29(0.8)$ & 0.332 \\
\hline VTE & $19(1.9)$ & $62(1.9)$ & 0.939 & $43(1.1)$ & 0.069 \\
\hline Cardiac complication $^{\mathrm{f}}$ & $7(0.7)$ & $10(0.3)$ & 0.092 & $4(0.1)$ & 0.001 \\
\hline Shock/sepsis & $81(7.7)$ & $270(8.3)$ & 0.734 & $112(3.0)$ & $<0.001$ \\
\hline Unplanned intubation & $12(1.2)$ & $29(0.9)$ & 0.410 & $7(0.2)$ & $<0.001$ \\
\hline $\begin{array}{l}\text { Bleeding requiring } \\
\text { transfusion }\end{array}$ & $98(9.6)$ & $279(8.6)$ & 0.299 & $140(3.7)$ & $<0.001$ \\
\hline Renal complication ${ }^{\mathrm{g}}$ & $11(1.1)$ & $33(1.0)$ & 0.853 & $12(0.3)$ & 0.002 \\
\hline On ventilator $>48 \mathrm{~h}$ & $9(0.9)$ & $29(0.9)$ & 0.985 & $12(0.3)$ & 0.015 \\
\hline Organ space SSI & $111(10.9)$ & $311(9.6)$ & 0.207 & $173(4.6)$ & $<0.001$ \\
\hline
\end{tabular}

$L O S$ length of hospital stay, $S D$ standard deviation, VTE venous thrombosis, SSI surgical site infection

${ }^{\text {a}}$ Laparoscopic converted to open vs. open colectomy

${ }^{\mathrm{b}}$ Laparoscopic converted to open vs. laparoscopic colectomy

${ }^{\mathrm{c}}$ Overall morbidity: Wound infection, pneumonia, urinary tract infection, VTE, cardiac complication, shock/sepsis, unplanned intubation, bleeding transfusion, renal complication, on ventilator $>48 \mathrm{~h}$, organ space SSI, and leak

${ }^{\mathrm{d}}$ Clavien-Dindo III-IV: cardiac complication, shock/sepsis, unplanned intubation, renal complication, on ventilator $>48 \mathrm{~h}$, organ space SSI, and reoperation

${ }^{e}$ Wound infection: superficial SSI, deep incisional SSI, or wound disruption

${ }^{\mathrm{f}}$ Cardiac complication: cardiac arrest requiring CPR or myocardial infarction

${ }^{\mathrm{g}}$ Renal complication: progressive renal insufficiency or acute renal failure times $(188 \pm 73 \mathrm{~min})$ compared to the planned open approach group $(166 \pm 83 \mathrm{~min})(P<0.001)$.

Compared to the laparoscopic group, the conversion to open group demonstrated significantly higher rates of overall morbidity $(26.9 \%$ vs $13.7 \%, P<0.001)$, serious morbidity $(16.4 \%$ vs $7.5 \%, P<0.001)$, readmission $(17.6 \%$ vs $10.3 \%, P<0.001)$, reoperation $(4.9 \%$ vs $3.1 \%, P=0.004)$, ileus $(20.1 \%$ vs $9.6 \%$, $P<0.001)$, longer LOS (6.1 \pm 7.6 vs. $4.9 \pm 7.6$ days, $P<0.001)$, and longer operative times $(188 \pm 73$ vs $152 \pm 66 \mathrm{~min}, P<0.001)$ (Table 2). There was no statistically significant difference in the rate of anastomotic leak ( $4.1 \%$ vs. $3.1 \%, P=0.105)$.

\section{Adjusted outcomes}

After adjusting for clinically relevant covariates, conversion to open was not associated with an increased risk of overall morbidity (OR 1.12, 95\% CI $0.94-1.30, P=0.238$ ) or serious morbidity (OR 1.20, 95\% CI 0.98-1.46, $P=0.074$ ) when compared to the planned open approach group (Table 3). That being said, patients who underwent a laparoscopic colectomy exhibited a reduced risk of morbidity when compared to patients undergoing a planned open colectomy (Table 3).

\section{Discussion}

The findings of this study demonstrate that when laparoscopic colectomies are converted to open, there is no increased risk of overall morbidity or serious morbidity when compared to a planned open procedure. This study adds to the growing body of literature suggesting that 
Table 3 Multivariable logistic regression assessing the association between operative approach and postoperative morbidity

\begin{tabular}{|c|c|c|c|c|}
\hline & \multicolumn{2}{|c|}{ Unadjusted analysis } & \multicolumn{2}{|l|}{ Adjusted analysis } \\
\hline & OR $(95 \%$ CI $)$ & P-value & OR $(95 \% \mathrm{CI})$ & P-value \\
\hline \multicolumn{5}{|l|}{ Overall Morbidity $^{\mathrm{a}}$} \\
\hline \multicolumn{5}{|l|}{ Operative approach } \\
\hline Open colectomy & Ref. & & Ref. & \\
\hline Conversion to open colectomy & $0.93(0.79-1.09)$ & 0.355 & $1.12(0.94-1.30)$ & 0.238 \\
\hline Laparoscopic colectomy & $0.40(0.35-0.45)$ & $<0.001$ & $0.52(0.46-0.59)$ & $<0.001$ \\
\hline \multicolumn{5}{|l|}{ Serious Morbidity ${ }^{\mathrm{b}}$} \\
\hline \multicolumn{5}{|l|}{ Operative approach } \\
\hline Open colectomy & Ref. & & Ref. & \\
\hline Conversion to open colectomy & $1.03(0.86-1.25)$ & 0.724 & $1.20(0.98-1.46)$ & 0.074 \\
\hline Laparoscopic colectomy & $0.43(0.37-0.50)$ & $<0.001$ & $0.55(0.46-0.64)$ & $<0.001$ \\
\hline
\end{tabular}

OR Odds Ratio, $C I$ Confidence Interval

${ }^{a}$ While adjusting for age, race, ASA class, diabetes, smoking status, steroid use, dyspnea, COPD, hypertension, bleeding disorder, weight loss $>10 \%$, hematocrit levels, white blood cell count, BUN levels, creatinine levels, pre-op transfusion, mechanical bowel prep, pre-op oral antibiotic, organ removal procedures, fistula, and preoperative sepsis

${ }^{\mathrm{b}}$ While adjusting for age, sex, race, ASA class, diabetes, smoking status, steroid use, bleeding disorder, weight loss $>10 \%$, hematocrit levels, white blood cell count, creatinine levels, pre-op transfusion, mechanical bowel prep, pre-op oral antibiotic, organ removal procedures, fistula, and preoperative sepsis laparoscopy may be a favorable option for CD patients, as the benefits of laparoscopic surgery may potentially balance the risks associated with converting the procedure to open.

Consistent with prior studies, we found that the conversion rate among CD patients was relatively high at $21 \%[13$, 14]. This is presumably due to the ongoing inflammatory process that decreases the clarity of the anatomy and subsequently makes the dissection and exposure more challenging. In the literature, conversion rates in $\mathrm{CD}$ have ranged from as low as $15 \%$, to as high as $70 \%$, but are typically reported between 20 and $25 \%$ [13, 14]. This high variability can be attributed to both the different definitions of conversion that exist in the literature, as well as the discrepancy in surgical indication between primary and recurrent disease, with the latter having much higher rates of conversion [22].

Interestingly, conversion to open was not an independent risk factor for postoperative morbidity when compared to a planned open approach. A meta-analysis by Giglio et al. in 2015 demonstrated comparable outcomes between converted laparoscopic colorectal resections and planned open resections, except for a higher risk of wound infection in the conversion group [10, 22]. However, our data did not show any statistical difference in the rate of wound infection between the two groups. These conflicting data could be due to the fact that the aforementioned studies describe a heterogenous patient population, and included both benign and malignant disease, diseases of both the rectum and colon, and a variety of operation types. This was not the case in our study, which had a well-defined population of CD patients undergoing elective procedures.
Furthermore, our findings differ from prior studies in rectal cancer patients, where conversion was found to be a risk factor for anastomotic leak, among other post-operative complications [23]. It is important to note though, that CD and rectal cancer represent different disease processes, with each requiring different types of resections and anastomoses. Our study is one of the first to demonstrate no association between conversion and anastomotic leak among this unique patient population of $\mathrm{CD}$ patients.

Several limitations of this study should be recognized. First, the retrospective nature of this study makes our analyses susceptible to residual confounding. We attempted to minimize this by implementing strict exclusion criteria to create a homogenous population focused on CD patients. Second, we were limited by the variables provided within NSQIP, which unfortunately lacked data regarding the use of biologics, disease-modifying anti-rheumatic drugs, and other immunosuppressants, which may play a key role in surgical outcomes [24]. We also did not have information on the postoperative course of the disease, and whether conversion to open influenced disease recurrence among $\mathrm{CD}$ patients. Other important factors not reported within the database included IBD-associated complications such as the presence of phlegmon, abscesses, or strictures, adhesions from previous abdominal surgery, recurrent or primary disease, and preoperative nutritional status. Since data regarding IBD severity was missing, we used variables such as concurrent small bowel resection, concurrent gynecological resection, and concurrent fistula takedown as surrogates for more complicated CD. 
Another limitation that could not be considered was surgeon experience and volume, which greatly influences the decision to undergo surgery, the choice of operative approach, the need for conversion, and whether an anastomosis or ostomy is performed. This lack of information precluded us from determining the reasons for conversion to open, as we were not able to delineate whether patients were converted for technical reasons, or whether intraoperative complications occurred. NSQIP also does not include data regarding the timing of conversion from laparoscopic to open. This is another important factor that can influence postoperative outcomes, as previous studies have associated delayed conversions with worse short-term and oncologic outcomes in colorectal cancer patients [25].

\section{Conclusions}

In this study, we demonstrated that converting laparoscopic colectomies to open produced similar outcomes as a planned open approach among $\mathrm{CD}$ patients, and that conversion was not an independent risk factor for postoperative morbidity. While choice of operative approach should be based on individualized preoperative risk factors, laparoscopic surgery may remain a favorable option, as the potential risk of conversion does not appear to confer undue risk among $\mathrm{CD}$ patients.

Acknowledgements Mr. Edwin Lewis has provided generous support for Dr. Efron's Department of Surgery Research Fund.

Authors' Contributions Rebecca Sahyoun - Concept, design, interpretation of data, drafting and revising manuscript, final approval, accountable for all aspects of the work. George Q. Zhang - Design, interpretation of data, drafting and revising manuscript, final approval, accountable for all aspects of the work. Brian D. Lo - Design, Interpretation of data, revising manuscript, final approval, accountable for all aspects of the work. Miloslawa Stem - Design, data analysis and interpretation, revising manuscript, final approval, accountable for all aspects of the work. Chady Atallah - Revising manuscript, interpretation of data, final approval, accountable for all aspects of the work. Peter A. Najjar - Revising manuscript, interpretation of data, final approval, accountable for all aspects of the work. Jonathan E. Efron Revising manuscript, interpretation of data, final approval, accountable for all aspects of the work. Bashar Safar - Concept, design, interpretation of data, revising manuscript, final approval, accountable for all aspects of the work.

Funding None.

Data Availability No.

\section{Declarations}

Conflict of Interest The authors have no conflict of interest to declare that is relevant to the content of this article.
Ethical Approval This study was approved by the Johns Hopkins School of Medicine Institutional Review Board.

\section{References}

1. Loftus EV, Schoenfeld P, Sandborn WJ (2002) The epidemiology and natural history of Crohn's disease in population-based patient cohorts from North America: a systematic review. Aliment Pharmacol Ther 16(1):51-60

2. Lichtenstein GR, Shahabi A, Seabury SA, Lakdawalla DN, Espinosa OD, Green S, et al 2020 Lifetime economic burden of Crohn's disease and ulcerative colitis by age at diagnosis. Clinical Gastroenterology and Hepatology 18(4):889-897.e10.

3. Cosnes J, Gower-Rousseau C, Seksik P, Cortot A (2011) Epidemiology and natural history of inflammatory bowel diseases. Gastroenterology 140(6):1785-1794

4. Panteleimonitis S, Ahmed J, Parker T, Qureshi T, Parvaiz A (2017) Laparoscopic resection for primary and recurrent Crohn's disease: A case series of over 100 consecutive cases. Int J Surg 47:69-76

5. Tan JJ, Tjandra JJ (2007) Laparoscopic surgery for Crohn's disease: a meta-analysis. Dis Colon Rectum 50(5):576-585

6. Umanskiy K, Malhotra G, Chase A, Rubin MA, Hurst RD, Fichera A (2010) Laparoscopic colectomy for Crohn's colitis. A large prospective comparative study. J Gastrointest Surg 14(4):658-663

7. Moghadamyeghaneh Z, Masoomi H, Mills SD, Carmichael JC, Pigazzi A, Nguyen NT et al (2014) Outcomes of conversion of laparoscopic colorectal surgery to open surgery. JSLS J Soc Laparoendosc Surg. 18(4). https://doi.org/10.4293/JSLS.2014.00230

8. Belizon A, Sardinha CT, Sher ME (2006) Converted laparoscopic colectomy. Surg Endosc Other Interv Tech 20(6):947-951

9. Gonzalez R, Smith CD, Mason E, Duncan T, Wilson R, Miller $\mathrm{J}$ et al (2006) Consequences of conversion in laparoscopic colorectal surgery. Dis Colon Rectum 49(2):197-204

10. Masoomi H, Moghadamyeghaneh Z, Mills S, Carmichael JC, Pigazzi A, Stamos MJ (2015) Risk factors for conversion of laparoscopic colorectal surgery to open surgery: does conversion worsen outcome? World J Surg 39(5):1240-1247

11. Schmidt CM, Talamini MA, Kaufman HS, Lilliemoe KD, Learn P, Bayless T (2001) Laparoscopic surgery for Crohn's disease: reasons for conversion. Ann Surg 233(6):733

12. Alves A, Panis Y, Bouhnik Y, Marceau C, Rouach Y, LavergneSlove A et al (2005) Factors that predict conversion in 69 consecutive patients undergoing laparoscopic ileocecal resection for Crohn's disease: a prospective study. Dis Colon Rectum 48(12):2302-2308

13. Moorthy K, Shaul T, Foley RJ (2004) Factors that predict conversion in patients undergoing laparoscopic surgery for Crohn's disease. The American journal of surgery 187(1):47-51

14. Mino JS, Gandhi NS, Stocchi LL, Baker ME, Liu X, Remzi FH et al (2015) Preoperative risk factors and radiographic findings predictive of laparoscopic conversion to open procedures in Crohn's disease. J Gastrointest Surg 19(6):1007-1014

15. About ACS NSQIP [Internet]. Available from: https://www.facs. org/quality-programs/acs-nsqip/about. Accessed 9 Dec 2019

16. ACS NSQIP Participant Use Data File [Internet]. Available from: https://www.facs.org/quality-programs/acs-nsqip/ participant-use. Accessed 9 Dec 2019

17. Complete blood count (CBC) [Internet].; 2018 [updated dec.19]. Available from: https://www.mayoclinic.org/tests-procedures/ complete-blood-count/about/pac-20384919. Accessed 9 Dec 2019 
18. Blood urea nitrogen (BUN) test [Internet].; 2019 [updated July 02]. Available from: https://www.mayoclinic.org/tests-procedures/ blood-urea-nitrogen/about/pac-20384821. Accessed 9 Dec 2019

19. Creatinine test [Internet].; 2018 [updated Dec. 22,; cited 12/04/19]. Available from: Creatinine test.

20. Dindo D, Demartines N, Clavien P (2004) Classification of surgical complications: a new proposal with evaluation in a cohort of 6336 patients and results of a survey. Ann Surg 240(2):205-213

21. Hosmer DW Jr, Lemeshow S (2013) Applied logistic regression, 2nd edn. John Wiley, NY

22. Giglio MC, Celentano V, Tarquini R, Luglio G, De Palma GD, Bucci L (2015) Conversion during laparoscopic colorectal resections: a complication or a drawback? A systematic review and meta-analysis of short-term outcomes. Int J Colorectal Dis 30(11):1445-1455

23. Liu X-H, Xian-rui Wu, Zhou C, Zheng X-B, Ke J, Lan P (2018) Conversion is a risk factor for postoperative anastomotic leak in rectal cancer patients - A retrospective cohort study. Int J Surg 53:298-303
24. El-Hussuna A, Andersen J, Bisgaard T, Jess P, Henriksen M, Oehlenschlager J et al (2012) Biologic treatment or immunomodulation is not associated with postoperative anastomotic complications in abdominal surgery for Crohn's disease. Scand J Gastroenterol 47(6):662-668

25. Kotze PG, Saab MP, Saab B, da Silva Kotze, Lorete Maria, Olandoski M, Pinheiro LV, et al (2017) Tumor necrosis factor alpha inhibitors did not influence postoperative morbidity after elective surgical resections in Crohn's disease. Dig Dis Sci 62(2):456-464

26. Kim IY, Kim BR, Kim YW (2017) Impact of timing of conversion to open surgery on short-term and oncologic outcomes in patients undergoing minimally invasive surgery for colorectal cancer. Am Surg 83(1):71-77

Publisher's Note Springer Nature remains neutral with regard to jurisdictional claims in published maps and institutional affiliations. 